\title{
Build trees
}

\author{
M. Despang \\ College of Architecture, University of Nebraska, Lincoln, USA \\ Despang Architekten Hannover, Germany
}

\begin{abstract}
This conference was held in a lodge in the "New Forest". This is an ideal environment to make the conference participants aware of the topic, addressing wood as nature's most direct and oldest building product, which has the greatest potential for helping the world into a postfossil future. Although wood is the most organic material, when it comes to public appreciation as a building material, it is not ranked highly. The author will question and answer how architecture technologically and aestetically can treat wood as an "up-to-date" and "state of the art (and architecture)" building material truly belonging to today's world. The author will show by means of students', colleagues' and personal work, how wood can create a sustainable architectural space and form evoking respect and appreciation from all human senses. Both practicing in Hannover, Germany and teaching in Lincoln, Nebraska, USA, the author will introduce in his paper the intercultural approach to wood research in natural building design. Work in progress and widely published built projects will illustrate the strategies for improving the environment with wood. The author's recent experience with the new TMT (Thermal Modification Technology) and the results of his participation in the 4 European Thermowood conference in February 2006 in Leipzig, Germany will be shared with the conference participants. The paper presentation will point out the challenges and potential of rethinking and reinventing wood as the building material for a future related to postfossil nature.
\end{abstract}

Keywords: postfossil Midwestern architecture, progressive monolithic wood structures, Thermo Modification Technology, "Passivhaus” technology.

\section{Introduction}

Compared to the hard sciences architecture tends to have a lesser grade of innovation. Compared to the progression in natural, medical and computer-aided 
science in the last century, building technology has nearly stagnated at a medieval level. The mainstream of architectural application is little influenced by the cutting-edge architectural research. On the other hand sheltering dramatically impacts the human environment. Architects should utilize innovative research such as eco-friendly building concepts tremendously helping to preserve the global environment. For example, due to a forestry mandate by the German government in 1999 Germany saw an increase of wood buildings from today $9 \%$ to $35 \%$. This would compensate in 8.5 million tons of coal oxidant per year. Since building with wood obviously makes common sense, a conclusion could be to strategize and seek innovation from tradition creating buildings out of nature's purest renewable material which is the oldest building tradition in the world. Wood, as compared to stone, has always been more appealing. The material's advantages are easiness to work with simpler tools and machinery and being lively like human beings. One might think by this observation, that wood is the ideal material to build with and which is the favorite in modern building application. Reality however, looks different. In the following presentation, reasons for contemporary human problems with wood will be investigated and possible strategies on how to improve.

\section{Analysis}

Both academic and professional locations of Despang Architekten in Lincoln, Nebraska, USA and Hannover, Germany serve as case studies revealing both regions beginning from shared roots have emerged quite differently. What they have in common are the skeptics about wood as a primary building material, although both regions on different continents have intensively been growing trees. The traditional northern German half-timbered structure restricts use of wood already to a necessary minimum, could not survive with the dominantly pioneers from Germany in Nebraska, who were coming to settle on a treeless prairie. Since then, Nebraska systematically improved and initiated the "Tree City" initiative by the Arbor Day Foundation [1]. The foundation oversees the Morton's family enthusiasm for regional and worldwide greening.

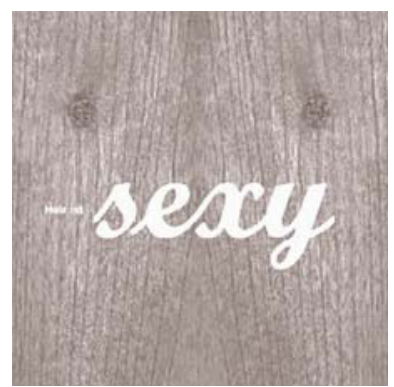

20

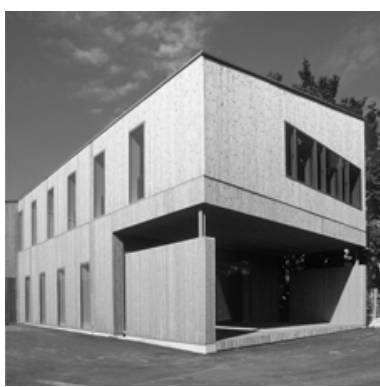

5

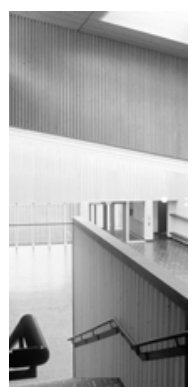

5

Figure 1. 
However wood still almost exclusively appears in the predominant wooden platform, the former balloon frame structure system. This might be seen as in the tradition of the German ancestors and their half-timbered system when comes to the efficiency in using wood as little as possible and minimize the structure to tiny studs. The lack of thermal building mass in the USA leads to the introduction of air-conditioning as the standard, as the ultima of unsustainability. And the outside of the wooden home appears like the common shared ideal of a solid home, symbolized by brick or stone veneer and more and more plaster cladding or vinyl siding as a fake reference to the wooden heritage.

In northern Germany due to energy building codes, what was formerly structural part of the wooden posts is made by concrete masonry units. They are surrounded by insulation, but yet on the outside they are sheathed with a replication of the half-timbered structure, neglecting the originating authentic tectonical notion to degrading as a wallpapering illusion.

Almost like the new world's "woody cars" with their wood revealing plastic foil glued to the sides of the automobiles, sentimentally recalls the former structural making of cars out of wood for the body. This raises the question, why wood as a material is so positively responding to nature and is so little appreciated in natural condition? Finding the answer needs surprisingly more than architectural investigation, because the reason might be more sociologically/psychologically related than architecturally. Discussing the issue with specialists in this field, the advantage of wood being organic and similar to the human being turns out to be at the same time and to the same extent its disadvantage. As expressed by the media in western culture only the forever young and virgin appealing human beings are accepted. In opposition, any natural aging process is rated down. In the media this phenomenon is drastically expressed by beauty surgery series and the equivalent in the building world in terms of wooden facades. These are periodically coated with a white paint, which refers back to brightening toothpaste.

This fakeness in using more the imagery of a wooden building rather than as the concrete physical appearance has a long tradition since European romanticism. For instance, the King of Prussia, Friedrich Wilhelm IV, in 1847 tried to cure the homesickness of his Bavarian born wife, Elisabeth, by building her a Bavarian log cabin in the center of the Wilderness Park in Potsdam [2]. Following World War II the leader of the socialistic East "German Democratic Republic" Erich Honecker, although praising and practicing a strict modernistic architectural approach for the people, chose for himself this so called "Bavarian house" as a cozy background for private and official representations. In an almost exclusively historical pattern former East Germany is rebuilding the cultural heritage after the reunification of November 1989, specifically in picturesque areas with a rich wooden architectural history like the "Baederarchitektur" [3] on the island of Ruegen. This compared to the new urbanism in the USA seeking the solution of healing the contemporary human being with the realm of old-fashioned craftsmanship and details. The desire for the wooden vernacular has recently been in the process of being professionally touristically engineered and being promoted by the leisure industry. Referring to 
the aura in the turn of the $20^{\text {th }}$ century, lodges in the USA, like Robert Reamer's groundbreaking Old Faithful Inn in the Yellowstone National Park or the 1936 Oregon Timberland Lodge, today's clever hotel managements are trying to build upon the sentimentalities of people regarding these eras as opposed to contemporary, unpredictable and hectic times. Rarely do these enterprises make use of the historical predecessors as a spatial and tectonical starting point, to then find an own state of the art and architectural interpretation. In this new trend known as "parkitecture", most are rather literal replicas of the architecture of the "old times" representing only the "good ones". A positive exception to the rule is the Amangani Resort hotel in Wyoming [4], where the hotel chain's corporate office and Paris architect, Ed Tuttle, who grew up in the Pacific Northwest, was melting the cosmopolitan and the vernacular by basically focusing on the potential of space and views with natural preaged materials in a modern manner.

However showing aging both in human and building extend is generally disliked by the majority of people. A different attitude is to be found in the regions more exposed to nature's forces, as along the coasts or in the mountains on both the European and the American continent, where the tradition of wood construction and cladding transcends into a widely appreciated new wood architecture. The exposure to nature's power in the form of steady gusty winds helps in regulating the humidity and allowing the wood surfaces to get a more equal patina. This creates a natural look such as the face of the farmer in the plains or mountain women in the mountains, with an own beauty of the skin structurally carved by the wind and the sun. Taking a closer look and tracing a comparison from nature and the structure of the bark on the trunk of a tree to architecture, we see a potential of striking similarities in approaching a sustainable notion: the ultraviolet light darkens the wooden building skin as a protection for the surface below and carvings drain the humidity.

\section{Development/results}

The architectural work of Despang Architekten made use of this research when investigating the potential of sustainable wooden building concepts on a natural, yet truly modern and contemporary basis. In the case of the design for the school for mentally disabled children in Garbsen, Germany [5] this goal was achieved by seeking a materiality responding to the extremely strong demand of addressing all the five senses of these special children. On a small lot in an existing school complex, blending the urban edge into the surrounding landscape, a pavilion courtyard type organization was applied to integrate natural conditions in the form of bringing open space, light and air into the building. The tectonical concept was derived from an idea regarding of the substance of a section of a tree itself: inside a notion of stimulating bright wood, on the outside sheathed by a "crusted" protecting bark. To achieve a thermal mass equivalent to the favored monolithic stone and brick house and unlike the common wooden lightweight structures, the mass of the trunk was taken literally by applying the wood in a massive way. The board staple-structure [6] insulates already rather well, so an average amount of insulation applied on it, achieves a much better $\mathrm{u}-$ 
value. This system of nailing the boards to each other in a structurally engineered way, so that a slab results, was chosen for the application for the entire structure of load bearing walls and ceilings. Julius Natterer, Professor at the Ecole Polytechnique Fédérale de Lausanne, Switzerland and main mentor of the system, calls a social structure, where the weakness of one member (board) is compensated by the other ones [7]. This structural/tectonical principle nicely describes and stands as well for the pedagogical concept of solidarity being the primary strategy in the education of mentally disabled children. In nailing the boards, instead of laminating them to each other the system is emission free.

The goal of a consistent appearance outside matching the vertically louvered surface of the inside, the same pine boards could be used, by applying the emerging and innovative TMT, intensively researched and promoted by the "ihd / Institut fuer Holztechnologie Dresden gGmbH", Germany [8]. Whereas untreated pine wood does not provide the affordable resistance against biological and insect attack, this improvement upgrades the resistance of the wood remarkably.

The public in general appreciates darkened, tanned and evenly textured wood characteristic for trees in seasonless regions which are mainly tropical areas. The massive and vast diminishing of the tropical rain forest is scientifically proven to have a hazardous impact on the global climate. However the TMT has been mainly invented to enhance the resistance against biological and insect attack, occurring based upon high humidity. The main environmental advantage of TMT is based upon another phenomenon. The exposure to heat and pressure let the wood turn dark and by this makes it attractive as an alternative for tropical hardwood. This way TM-wood helps to preserve the tropical rainforests and the global climate. In addition, the untreated wood is serving the local environment by having been regional softwood trees prior to becoming a TMT product and in this previous function, intensively helps to convert coal oxidant into oxygen. Even the energy for the modification process can be recruited from the natural resource circle itself, by firing the heat chambers with the same fast growing regional wood which is modified.

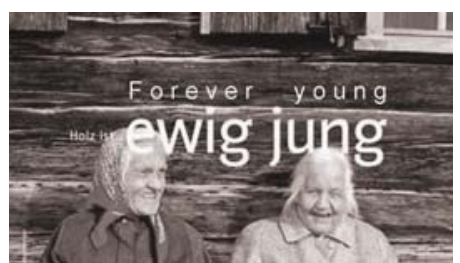

20

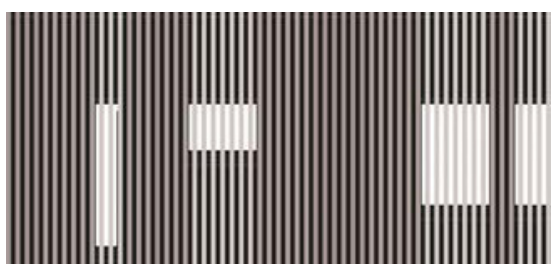

9

Figure 2 .

While technologically convincing, on an emotional level the material yet still has to find an own identity, a soul, as a requirement for being accepted, which again is the basic requirement for sustainability. The material therefore has to overcome the substitutional character. The potential for an own realm is yet 
obvious, but has to be explored furthermore on a broader architectural level. For example tropical hardwood, due to the lack of seasons, is often missing grain. The variety of these natural textures of local softwood can be strategically used, as the tectonics of the school in Garbsen demonstrates. Throughout the fine rhythm of the boards and the battens system, the texture of the pine wood works almost as a natural ornamentation.

The heat treated pine wood, made by diminishing the crystal water in the wood, already reacts like the tanned human skin, protecting the cells underneath and ages equally.

As part of the vertical tectonical sheathing elements like windows, gutters and down sprawls are integrated flush into the surface. Equally exposed to sun and air, like the human skin of the mountain women, the façade of the building in this way has the chance to age in honor. This result is a higher grade of appreciation and acceptance for the architecture, because the architecture makes use of the tectonical principles and makes people collectively agree like they do on the natural beauty of a tree trunk.

Despang Architekten's project, which is building upon the previous experience but yet pushing the envelope to an even further extent, is a kindergarten building project in Hannover, Germany [9]. For another public client with a limited budget, the goal was to create a building with high comfort, while assuring a natural environment for the children. In addition to ending fossil resources, the building is mostly independent from this kind of energy. The building is situated in a consistent 1960's neighborhood, with a high urban quality and replaces an existing structure from 1970. The neighboring structure is a sustainable neighborhood grocery store center designed by Despang Architekten in 2004 [10] which received the Lower Saxony States Award of Architecture [11] that year.

The chair of the jury, Professor Carsten Roth, both of Hamburg and Braunschweig, Germany and Denver, Colorado honored the concept for the both rigid and poetic structure of a concrete frame. In terms of a neighborhood kindergarten building, the existing site with a yard of mature trees was carefully adapted to redesign the kindergarten building type. As a research result of the Garbsen school, the north side is treated in a similar manner, hosting the serving rooms, sheathed by a screen of heat modified wood battens which change from opaque to opal running over the solids and voids of the surface.

The approach of the application of the heat modified wood though goes beyond the achievements of the former one, by expressing the TMT process in the building design and using this as a creative exploration. In the areas of the windows, the brightest HM wood is applied, which is the one been processed the shortest time. In the closed wall areas the darkest one is used. In between, the transition from bright to dark will generate a notion of motion.

The application will enhance the character of TM wood and be of major contribution to the "no emission" building concept, which will be an opportunity to promote the material being rather unique than substitutional.

To keep the heat out in the summer and the cold in winter, highest insulation and thermal mass are incorporated. The search for the appropriate structural 
system lead linearly back from the contemporary most commonly executed American platform type, to it's ecological precedent, a 1973 case study home in Lungby, Denmark [12]. Surprisingly enough research sources trace knowledge about this as far back as the last major global awareness of ending fossil resources in 1970.

Similar, in the kindergarten project, TJI studs are used with a foot deep insulation out of cellulose as another aggregate condition and use of trees. The necessary thermal mass is provided by massive wooden ceilings, once again in the board-staple structure and a PCM (Phase Changing Material) enriched concrete floor slab, again disconnected from the earth by a foot deep insulation.

The curvilinear southern façade is entirely glazed and maximizes the solar gain and transition of space from the inside to the outside. The existing trees, in addition to custom made umbrellas, keep the building from overheating in the summer. Although neither a romantic log cabin nor the beloved stone building, this project will convince the client in the way of its environmental friendliness, as the building material instead of polluting, cleans the environment.

The project points out another important aspect by obeying all the parameters and applying all the tools of "passive house planning", but this alone does not yet generate a result which is satisfying from an architectural point of view. In other words green vocabulary does not automatically enable planners to speak a sustainable language, because architectural quality in a balanced relation of form, space and tectonics needs to be integrated to make the building pleasing to the occupants and endure or be able to be adapted, which is one of the most important integral aspects of sustainability. As much as the lack of environmental building sensitivity has been a concern in the past, the lack of innovative architectural character of "passive houses" might be a problem in the future. The questionable charm of glued together styrofoam boxes can already be seen as a problematic issue, keeping green building design away from becoming influential on a broader, widespread level. The kindergarten design by Despang Architekten demonstrates that passive house technology is not an aim but a tool to create ecological architectural space. To deal with these physically generated parameters is not the final destination but the starting point in greening design. The architectural exploration has to give these somehow restricted, nature-given parameters spatial character. And the design has to donate to the building a distinct, unpredictable character responding to the individual inspirations of exteriorities and interiorities as is always and ever the case with good architectural design, no matter if green or not. Wood as nature's oldest and regarding the future most emerging building material is ideal because it is inheriting both pragmatically and poetic quality.

However in regard of a global potential, wood has yet to be introduced to a wider audience by applying to a broader range of architectural building types, like the train stations designed for the Expo 2000 in Hannover by Despang Architekten [13]. However most important is to promote wood in terms of the organic human attitude in the domestic building typologies. The rental "treetop condominiums" by Despang Architekten in Hannover is an example of using wood in a building type commonly and traditionally in a particular 
geographically area not familiar with wood. In this case the sentimental notion of wood as the structural material of a tiny half-timbered house which was previously occupying the lot is used to code and accentuate the areas of most intense human occupation, blending the space between the private and the public. Wood is by this transformed from a structural literal level to an abstract enveloping one.

Using wood is from the matter of a wide public appreciation most important in small scale domestic building types, like in the case of the "house K." [14] and the "wooden feathery extension" project by Despang Architekten [15], again in Hannover. Adding a one room extension and a canopy to an existing old house creates a new sense of place and a transition of space from the inside to the outside. In this case the physical capabilities of camballa wood enabled a concept of structure and architecture to blend into each other as integrative parts and work primarily with light and shade as major architectural components, like bamboo does in the natural world. Worth examining is once again the calculated notion of a comfy and warm environment, created by the material's unique physical quality. The decades of the 1950s and 1960s, being influenced by the design of northern European countries, can be strategically seen as predominantly taking advantage of this. Instead of staying a local phenomenon, sensual architecture emerged to a global extent and excitingly down to the ordinary average single family house. The 1950s domestic case studies almost automatically resulted in relating to natural conditions, as blurring the boundaries from the inside to the outside, sun gaining floor to ceiling windows to the south and ventilating courtyards as "low technology" natural cooling devices. This notion is represented by the tropical hardwood resembling covers of the recent books about the west coast phenomenon of the "Eichler homes" [16] or about the more vernacular "ranch homes" [17]. The rising appreciation in this legacy is as well an indication of a potential of wood being strongly associated with progressive housing for a wide range of the population in the USA.



19



20

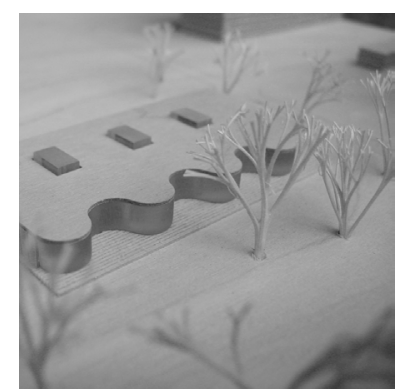

9

Figure 3. 


\section{Execution/conclusion}

Researchers at the College of Architecture at the University of Nebraska-Lincoln will investigate the future potentials of the progressive Midwestern mid-century homes legacy. Starting from the analytic precedents from the past, the further goals and objectives are to trace the spatial, tectonical, environmental and social potential of wooden buildings into the future. The experience of professional practice of the instructors will help and encourage the students. In particular the Nebraskan Assistant Professors Jeffrey L. Day [18] with offices in San Francisco, California and Omaha, Nebraska and Martin Despang in Hannover, Germany will share their knowledge of investigation in the creative potential of wooden prefabrication production with the students for the benefit of the teaching and research exploration. Whereas Martin Despang's School in Garbsen, Germany was experimenting with automated prefabricated massive elements, creating efficient, ready made and thermal, acoustical and sensual qualified components, Jeff Day's "Wood Island House", deals with the challenging issue of defining an organic domestic space by using cutting-edge computer technology both in design and fabrication.

Leading in building energy consumption, the USA has to use the architectural academic freedom to address the potential of ecology in building design more aggressively, especially in the Midwest, with perfectly given natural resources of sun and wind. Rising energy costs might even give them the chance to receive a wider public audience and interest, making a virtue out of the dilemma and introduce progressive architectural dimension once more to the citizens of cities, communities, neighborhoods or just the single middle income family. In collaboration with involved faculty at the College of Architecture at the University of Nebraska-Lincoln, this issue will be addressed more intensively in architectural education.

Projects to be resolved are by intention small, giving students a chance to study the issue in more depth, rather than creating huge corporate architectural visions lacking sensitivity for the detail. Masters student Daniel Siedhoff is currently preparing for his master thesis, re-designing a house on a lake, being design/builder with hands on activity. Colleague Alissa Piere uses her childhood experience of having grown up close to the Winnebago Indian Reservation north of Omaha, Nebraska to re-think the domestic reality of contemporary Indian life [19].

For both students the investigation is a process getting back to their roots. Their ancestors instinctively knew how to survive in the harshness of the prairie plains by physically protecting themselves from the north wind and opening to the south sun, in this case literally "building" trees. When it comes to the point of creating truly contemporary ways of living environments in the beginning $21^{\text {st }}$ century, this generation will be looking forward, in a highly advanced modern global world, seeing the tree as a metaphor for creating self sustainable and rerooted architectural organisms. 


\section{References}

[1] www.arborday.org.

[2] www.bayerisches-haus.de.

[3] Reno Stutz, Thomas Grundner, Baederarchitektur, Hinstorff Verlag Gmbh 2004.

[4] Lauren Bernstein, Lodges de Luxe, United Hemisphere 012006.

[5] Baumeister B4 2003, l'architecture d'aujourd'Hui 374: 2003, Holzbauatlas 2003, DETAIL 1/2 2004, tec 21102004.

[6] Herzog, Natterer,..., Holzbauatlas Birkhaeuser 2003.

[7] www.iez-natterer.de.

[8] www.tmt.ihd-dresden.com.

[9] Passive house kindergarten, Hannover, Germany scheduled for Fall 06.

[10] db 092004.

[11] www.aknds.de.

[12] A travel report from a journey to Denmark and south Sweden by students and faculty from the of the University of Munich in 1976 /1978, Arbeitskreis Excursion Daenemark und Schweden, Munich.

[13] DETAIL 04 2000, Wallpaper UK 05 2000, XS Thames \& Hudson UK 2001, C3 Korea 01 2005, Material for Design Princeton Architectural Press USA 2006.

[14] Cristina Del Valle, ,compact houses“, Bookslab 2006.

[15] DBZ 06 2000, C3 Korea 2003.

[16] Jerry Ditto, Lanning Stern, "Eichler homes“, Chronicle books 1995.

[17] Alan Hess, „Ranch House“, Harry N. Abrams, Inc. Pub 2004.

[18] www.minday.com.

[19] Alissa Piere, master thesis: "REZidential Housing, a prototype for the Winnebago reservation, UNL Spring 2006.

[20] Infodienst Holz 2006 campaign: "sexy", "Holz ist ewig jung- wood is forever young" + "Holz ist schlau - wood is smart". 